\title{
Iowa State University Beef Teaching Herd Feed Efficiency Selection - Year 1
}

\section{DOI:10.31274/air.12603}

Garland Dahlke, Iowa Beef Center; David Bruene, Beef Teaching Herd Superintendent, Iowa State University

\section{Summary and Implications}

Over the past 15 years there have been a number of research and extension efforts directed towards the improvement of feed efficiency in beef cattle. These efforts often involved herds other than the actual university's herd, but now Iowa State University's teaching herd has been enrolled and the developments will be made available as time moves on for the public to follow.

\section{Introduction}

The concept of feed efficiency is pretty straight forward. It deals with the productivity per unit of feed provided. This can be influenced by a number of environmental factors such as weather, feed quality, nutrient density, ration formulation, hormone implants, other feed additives and variation in animal care. The genetic component is what we were trying to influence in this project so the use of the weaning contemporary group is going to be our focus. Raw feed to weight gain will be recorded as well as the adjusted feed to gain calculated as the Beef Improvement Federation has recommended in years past and these will be made available for reference since many are accustom to seeing this data. What the farm will be using is the RFI, or residual feed intake, however in selection for the fact that this measure accounts for both maintenance efficiency as well as growth efficiency. It does not have strong correlations with other traits as feed to gain or even residual gain would have thus making it a useful tool in the selection scheme. RFI is an index value of sorts and one could also add other components such as lactation efficiency for the cow herd or even apply a dollar value to these efficiencies, but for our project we will keep things simple and not add other features.

The use of RFI can lead one astray since cattle that do not eat much and have minimal weight gain can sometimes appear to have a very good RFI. RFI in the business of cattle feeding saves money but weight gain is what generates revenue so it is necessary to maintain standards in the other performance traits when implementing this addition to the selection strategy.

\section{Materials and Methods}

Sixteen calves of Simmental and Angus background from the 80 cow ISU beef teaching, spring calving herd were weaned, vaccinated and allowed about one month of adjustment time to living on their own and to adjust to their new diet. The bull calves that were selected for the trial were those that would be considered as potential herd sires or for the biannual sale. The calves were placed in the Feed Intake Monitoring System (FIMS) at the ISU Beef Nutrition Farm. After a two-week adjustment period the bulls were weighed two days consecutively for on test weight and the test began.

The test ration contained a base level of hay and dry distillers, that was held constant throughout the feeding trial, along with corn silage and a supplement which both increased as dry matter intake increased for the bulls while on test. The ration Neg content averaged out to $0.5 \underline{0}$ $\mathrm{Mcal} / \mathrm{lb}$ of dry matter (ranged from 0.48 to 0.51 during the time fed), $53.7 \%$ DM, 39\% NFC and $15 \%$ physically effective NDF. Metabolizable protein supported 98 to $107 \%$ of the NE provision while the bulls were on test.

The test ran 71 days from September 22 through December 1. At the end of the test the bulls were fasted for 16 hours and weighed off. The data was processed using the Iowa Beef Center's Feed Efficiency Calculator that is available to the public from the Iowa Beef Center's website. An ultrasound for carcass backfat was not done due to the young age of the bulls, therefore the residual gain calculation $(\mathrm{RG})$ is incomplete.

\section{Results and Discussion}

Table 1 provides a summary of outcomes for the various measurements taken. The average results and minimum and maximums are interesting to study and they are values we may want to use as the metric to make statements on how we are progressing or regressing in our selection process, but these can be easily manipulated by yearly environmental variation. If we could hold all things constant, we could look at a measure like adjusted feed to gain and stop with that, but this is not possible. This poses a problem in terms of how we are to measure progress. We therefore need to make our comparisons within the weaning contemporary group and then focus on the variation that we observe. If we look at the standard deviation of residual feed intake (RFI) measures, a trait that we have never selected for in this herd, for instance we see a pretty large value. The mean for RFI is always zero due to the mechanics of its calculation, but as we start to provide

Copyright (C) 2021 by the Authors. This is an open access article published under the CC BY-NC license (https://creativecommons.org/licenses/by-nc/4.0/), which allows for non-commercial reuse with proper attribution. 
selection pressure this standard deviation should begin to shrink as should the standard deviation for dry matter intake since this also has not been part of the selection criteria. Average daily gain has always been a trait that has been selected and we can see that the standard deviation is considerably smaller than the other traits that were mentioned. Feed to gain measures contain both the ADG and the DMI components and they show an intermediate amount of variation as a result.

\section{Acknowledgements}

The authors would like to thank the staff of the ISU Beef Nutrition Farm for their assistance with this project. 
Table 1. Data summary of the first round of animal evaluation

\begin{tabular}{|l|l|l|l|l|l|l|l|}
\hline & $\begin{array}{l}\text { Start Wt. } \\
\text { lbs }\end{array}$ & $\begin{array}{l}\text { End Wt. } \\
\text { lbs. }\end{array}$ & $\begin{array}{l}\text { ADG } \\
\text { lb/day }\end{array}$ & $\begin{array}{l}\text { Avg. DMI } \\
\text { lbs/day }\end{array}$ & RFI & Adj. F:G & Raw F:G \\
\hline Average & 498 & 725 & 3.54 & 15.7 & 0.00 & 4.46 & 4.45 \\
\hline St. Dev. & 44 & 49 & 0.21 & 2.0 & 1.87 & 0.74 & 0.66 \\
\hline Min & 431 & 655 & 3.20 & 12.4 & -2.49 & 3.15 & 3.18 \\
\hline Max & 611 & 850 & 3.89 & 19.4 & 3.49 & 6.05 & 5.60 \\
\hline
\end{tabular}

*Note that Fat Cover was not determined in this data set, therefore the Residual Gain (RG) value is incomplete and disregarded. 